\title{
Working in Harmony with Nature: Physical and Mental Cultural Ecology as Motivators of inland Fishers in Bambalang, North West Cameroon
}

\author{
Fomba Emmanuel Mbebeb \\ The University of Bamenda \\ Forgako Elizabeth Gakuna \\ Regional Delegation of Fisheries and Animal Industries \\ North West Region, Cameroon \\ Kinge Marinoel Ngwenyi \\ Graduate Student \\ The University of Bamenda
}

\begin{abstract}
Emerging debates on work and nature interface have recognized cultural ecology as an adaptive mechanism capable of energizing work behaviors, and driving a sustainable future for fisheries. Cultural ecology has been positioned as a utilitarian facility capable of ensuring adaptability to occupational demands while preserving aquatic and marine resources. The paper submits that inland fishers integrate cultural patterning into mainstream fishery operations, which simultaneously acting as catalyst to eco-sensitive work behaviour. Despite the economic benefits, the paper equally laments that certain exploitative practices are fraught with predatory attitudes and behavior due to non-reverence of nature. Building on existing models of man-ecology interface, the study investigated whether material and mental cultural ecology has any relationship with occupational drives of inland fishers. Participants constituted 130 fishers (35.7\% females, $64.3 \%$ males) in Bamabalang, North West Cameroon, and a structured instrument was used to collect information. Descriptive statistics and regression were used for data analysis. According to results, physical ecology $(\beta=0.34 .4, t=41.142, P<0.01)$ and mental ecology $(\beta=0.337, t=4.045, P<0.01)$ were reported as determinants of occupational motivation of fishers. Results suggest that though cultural technologies are seemingly invisible in the operations of fishers, they should be captured and integrated into conventional adaptive modes to ensure productivity and marine ecosystem. Discussion is centered on current participatory fishery management system having homegrown eco-values, and challenges in bridging between economic and ecological interest. While advocating sustainability benefits of ecosystem-based fisheries management, the paper suggests further research areas on fatalistic beliefs and relationships with risk taking behaviour, safety and health of inland fishers.
\end{abstract}

Keywords: Nature, cultural ecology, physical, mental, motivation, sustainability, fishery sector

\section{Introduction}

Ecological science is an approach to a better understanding of the complex interrelationships between humans and the earth's ecosystem (Brenner, 2018), and its sustainability depends on cognitive, affective and behavior dispositions of occupants. It has been observed that rivers, lakes, seas and oceans, as well as plant and animal life are important to all human culture and form an explicit or implicit part of human beliefs (Chambers, 1999). This is closely associated with the concept of cultural ecology, an adaptive strategy that seeks to foster a user-friendly approach to environmental exploitation using cultural patterning. Cultural ecology has been defined as the scientific approach exploring the relationship between human society and natural environment in the process of sustainable livelihood (Lapka et al., 2012). This brings into light current debates in workplace ecology, where a harmonious relationship between work and nature is perceived as invaluable in the exploitation of ecological resources. Man-ecology interaction affects all facets of livelihood as man adjusts in the process of using cultural values to adapt to the environment. Therefore, Chambers (1999) explained that culture and utilitarian values are often closely interlinked so that resources with great utility value may be given a religious or ritual significance. 
This is mostly realized through occupational activities such as fishery, which has become a great source of economic development and subsistence for many, and where valuables such as water, fish species, nets, and practices are revered and even worshipped. Although fishery is a social and economic activity, Madakan et al. (2015) further explained that it is an essential component of the ecological system. Work therefore, does not only play a psychosocial and economic function, but equally a cultural ecology function since work is perceived as a cultural activity. In the fishery sector, culture demands occupational drives to satisfy needs and in the process, survival drives often affect the environment with great losses on marine biodiversity. With gross disregard for nature, man-ecology interface appears to be dominated by exploitative values due to survivalist tendencies. Although the motivation to work is moderated by social, cultural, and ecological norms, it is often determined by high economic interest and drives, and characterized by unsustainable consumption patterns (Fomba, 2012). Among others, distorted perceptions of the eco-system and predatory behaviors of users have been deployed by some fishers in the occupation. This is often due to deficiencies linked to knowledge values of fishers, and aggressive and imposing occupational practices due to societal demands.

Despite the fact that giant fishery enterprises are often accused for abusive exploitation, small scale endogenous activities have equally been held responsible for the depletion of marine ecology. This is common in specific socio-cultural contexts while adapting to immediate exigencies, and deviant work behaviors of fishers have often been accused. Since occupational behaviors are commonly determined by culture, Lakpa et al. (2012) emphasized the relevance of integrating cultural ecology into the crucial information processes about human adaptation with diverse human activities. Since manifestation of ecological crisis knows no boundary, the depletion of marine resources in small scale artisanal fishing has been of key interest to development actors. At times ecological crisis emanates from the management of projects since management boundaries that are ecologically meaningful are those that are determined by habitats and other ecological considerations (Cacaud \&Cosentino-Roush, 2016). Recognizing that fishery requires a multi-faceted planning that gives equal regard to economic, social and ecological considerations (Madakan et al. 2015), the occupation is expected to be sustainable, and fishers as actors are expected to protect biodiversity. Considering that water for artisanal fishers represents a source of food for the family and goods to sell at the market (Chambers, 1999), the use of cultural ecology as a framework emerges as a key response to challenges of sustainability in the process of exploiting aquatic resources. Perhaps, this could be attributed to the understanding that cultural and spiritual diversity dwell upon the beliefs and practices of indigenous and traditional peoples in relation to their use and conservation of biodiversity (Posey, 1999). This could explain why cultural ecology, which is a measure of adaptability to fishers in Bamabalang, is the main focus of the study. It explores fitness of cultural patterning, as a source of fishing energy to fishers, and how it is capable of balancing economic and ecological interest in the fishery sector.

\subsection{Bridging between occupational and ecological interest}

Increasing tension exists, tough seemingly invisible, between the fishing occupation and ecological sustainability, and this could be redressed by the force of cultural ecology. Cultural ecology attempts to understand existing relationship of man with environment and culture (Gun, 1980), and tries to bridge between economic interest and environmental justice. Though the concept of ecological adaptation underlies all cultural ecology, the procedures must take into account the complexity and level of the culture (Steward, 2006). One reason for this intricacy is that cultural forms are multiple as per the needs of the people, and this can influence people in different cultures to express different responses to the environment. This is evident with behaviour setting, where various settings have specific social and cultural definitions resulting from intended purposes, the type of occupant, and the activities taking place and their outcomes (Popovand \& Chompalov, 2012). The setting plus intended behaviors are more or less cultural patterning with behaviour episodes designed to serve specific functions, and which must be actualized to serve intended purposes of adaptation. Although participants of a setting have different background, experience diversity, contrast and contradictions, they have common points of sharing and learning. Since understanding ecological principles enables scientists to predetermine requirements necessary to establish a balanced ecosystem (Clovis, 2003), the compelling need for sustainability becomes imperative and requires the deep understanding of cultural ecology as a problem-solving strategy that needs to be harnessed in local contexts to promote sustainability. Since environmental behavior is fundamentally the product of culture, the social and behavioral sciences have become very active in promoting cultural ecology in occupational activities. While bridging the widening gap between economic benefits and sustainability, agents should take into consideration local realities and felt values of the people. 
Investing from below implies that the social and cultural dimensions of resources exploitation would be socially and culturally generated as a way of life of local people (Fomba, 2012), and this is where the strength of cultural ecology is derived. With this strategy, it becomes feasible that local ecological challenges can now be explored by traditional scientific disciplines in its diversities (Lakpa et al. 2012). In this respect, deviant environmental behaviour that depletes ecological resources can be resolved by the social and behavioral sciences. This stems from the fact that pro-ecological behaviors are derived from human interest and motives, and the greatest challenge to sustainability lies in behaviour change that is capable of promoting pro environmental behaviour. In this light, the concept of cultural ecology has been extended to explain divergent group responses with regards to perceptions and actions in occupational settings. This explains why the bizarre mentality of human being on destroying and conserving slogans warrants understanding the fundamental link between human psyche and our physical environment (Jena and Behera, 2017). If ecological culture generally refers to a set of goals designed to get rid of poverty, encourage participation to improve health, education and the economy (De Bustos, 2009), the role of psychology becomes projected as a catalyst for a strategic way forward. It would be recalled that work as a cultural value and livelihood strategy is inherent in modes of economic and social operations, and at times these depend on cognitive and behavioral orientations. From the spiritual value of a sacred spring to the daily catch of fish from a tropical reef, many communities have an intimate relationship with the water around them and the life it contains (Chambers, 1999). Consequently, there is more meaning in physical ecology as part of the ecosystem, demonstrating that an established relationship exists between cultural patterning and the people's socio-economic activities. This explains why environmental problems are often misconstrued due to disregard of cultural values about human adaptation to the ecosystem (Lakpa et al., 2012), and justifies why human behaviour is highly critical in environmentalism. There is no doubt that cultural ecology often dictates the way members adapt to emerging occupational demands, but communities have the primordial responsibility to inculcate work values that promote pro-environmental behaviour in order to ensure equity. It has been observed that cultural ecology becomes a critical factor in livelihood processes, a balancing factor that contributes to sustainability, which is fundamental to occupational success (Al-khawaja, 2015). This means that petty business ventures capable of satisfying the needs of fishers needs to embrace ecological values. In this respect, Fomba (2012) advanced that coupled with their potentials for engaging in green, rural economic practices, local people have been recognized for their natural expertise in practicing sustainable approaches to subsistence derived from their perceptions, attitudes, and ecological identity. This expresses the need for innovative occupational settings with relevant systems capable of promoting workplace ecology notwithstanding the nature and spread of the business operation. Furthermore, this is built on the premise that the sustainability of any culture is an essential aspect of cultural ecology, which basically defines the promotion of biodiversity in its entirety. Despite the fact that physical cultural ecology is very essential, the mental dimension remains critical in promoting positive attitudes in the process of adaptability. Balancing economic and environmental interest is fundamentally a cognitive problem and a sustainable balance has to start with behaviour change. This normally starts with cognitive change, attitudes and perceptions before the expression of overt environmental behaviors. Such activities are expressed through small social or familial subsistence enterprises that are having great potentials for employment, poverty alleviation, and environmental justice (Fomba, 2012). One of such activities is small scale artisanal fishing, where cultural ecology values and occupational behaviour can constitute sources of sustainability.

\subsection{Inland fishing and cultural patterning in Bamabalang}

The Bambalang Lake is found in Bamabalang community, Ndop, North West of Cameroon. The source of the lake, the Baminjin dam was created in the 1970's to increase water supply to generate electricity at Songlulu, and its surrounding villages. The Baminjin Dam overflew in a large area of Bambalang community and gave birth to a vast water body now called the Lake Bambalang. The lake grew in size and washed away homes, farmlands, raffia bushes and rendered many homeless. In addition, the water body disconnected villagers from their kins, traditional livelihood sources and socio-cultural facilities. The community was left without any immediate choice but to learn and live on inland fishing as a main occupation to sustain living. Fishers of this community consider the occupation as a source of nutrition, income for their well-being and dependents (Forgako, 2018).

Despite benefits derived from fishing, inhabitants of the community consider it as a way of life, recognizing its cultural significance and identity to the people of Bamabalang. Artisanal fishing normally differs in approaches, and this depends on the nature of ecological and cultural contexts of the place and people respectively. 
To the community, water is a key to their survival, and their relationship with water has become a major part of their identity, religious beliefs, ritual practices, and their daily engagements and concerns (Chambers, 1999). This reflects the way their values are patterned and recognized as facilities that can facilitate survival, and this has been projected through artisanal fishing activities. Government promotes modern fishing techniques so far as this occupation is concern, but fishers at times use rudimentary equipment like bamboo and wooden canoes, broken paddles, patched nets, hooks and traps to capture fishes. Apart from the material dimensions of technology used in the occupations, spiritual practices have been observed as very critical in their occupations. Their fishing activities have been interwoven with their cultural ecology and this has been demonstrated by traditional beliefs through fatalistic practices performed before, during and after fishing seasons. Crowes (2013) observed that incorporating spirituality in any ecological setting provides an additional way to construct knowledge, make meaning of experiences, and connect to established practices. It appears psycho-spiritual technologies such as cleansing rituals, appeasement of gods and the use of protective charms ensures protection of fishers, and appeases the water for a good catch. Such technologies also act as energizers to the fishers in carrying out their activities. The values internalized by fishers are drawn from wider community cognitions as factors capable of realizing their occupational motives. There is no doubt that this raises a lot of skepticism, questioning whether values are magic wands capable of facilitating performance in such a high risk work setting.

The Ministry of Livestock Fisheries and Animal Industries (MINEPIA) has been monitoring eco-friendly practices of fishers in order to improve marine ecosystem, and this is often realized in collaboration with stakeholders. This is the case of the Livestock and Fisheries Development Project (LIFIDEP), North West Region, which has provided technical and material assistance to fishers. A typical example is the training programme on Community Based Fisheries Management realized in collaboration with the North West Regional Delegation of Livestock, Fisheries and Animal Industries (DREPIA). Within the framework of this initiative fishing gears are provided to fishers, and in addition, their knowledge and skills are enhanced on the effective use of available cultural technologies in the fishing occupation. Through a pilot project MINEPIA has recently introduced and encouraged fishers of Bambalang to practice cage culture. This is a fishing method that uses existing surface water resources instead of using earth pond and concrete tanks and rivers. The competitive edge to marine ecology is that the method uses "Open Ocean" to confine fishes inside a mesh enclosure in their natural habitat. An experimental phase carried out with the community was quite successful and boosted the morale of the community though the question of continuity and sustainability is at stake. Cage culture is currently being used in the community by Camfish Co. Ltd, an enterprise that has been working closely and receiving technical assistance from MINEPIA. Despite the efforts of the Government and other stakeholders to put in place a strategic framework for the development of sustainable fisheries and aquaculture, the initiative remains a major challenge at the level of the community (Forgako, 2018). Although the approach seems to be dynamic enough to cultivate homegrown work values and incorporate them into conventional fishing strategy, there is skepticism whether this can enable fishers to adapt to their occupational setting. With the understanding that ethical, philosophical, belief systems and practices of indigenous people affect them (Posey, 1999), the question is whether cultural ecology of fishers can determine occupational motivation. Fishers are addicted to fatalistic beliefs with the use of cultural technologies such as talisman, beats, sacrifices and songs to calm storm, protect themselves and make a good catch, in lieu of conventional Personal Protective Equipment (PPE). One keeps on wondering if such practices can catalyze work behaviours of fishers. The lack of conservationist practices or reverence for nature may explain the high levels of environmental damage (Chambers, 1999), which is evident with the practices of bycactches, ghost fishing, discard, use of wrong gears and damage of habitat by the fishers. Precisely, this raises questions on the power of physical and psychological cultural ecology in energizing work behaviour of fishers. Owing to the recognition that human being significantly distresses the environment through exploitation of marine resources and damage of natural habitat with diminishing biodiversity (Jena \& Behera, 2017;Mmbaga, 2013), the disturbing question is whether cultural ecology can sustainably drive fishers to operate with an ecological mindset. A number of studies have been documented portraying a positive relation between spirituality, human wellbeing and environmental conservation (Crowe, 2013; Barrera-Hernandez et al., 2015), but none has addressed issues on cultural ecology in occupational setting in local communities. In Cameroon, some attempts have equally been made to incorporate cultural values into environmental management and sustainability with particular focus on occupational activities (Fomba, 2012; Forgako, 2018), but efforts are yet to be noticed in the psychological dimension of cultural ecology. 
From the foregoing analysis the researchers found it necessary to explore that relationship that exists between physical and mental cultural ecology as predictors of motivation of inland fishers of Bambalang, North Cameroon.

\section{Review of related literature}

This section explains concepts, present theories and review related works that have close links with cultural ecology and work behaviours. It starts with the clarification of key concepts as applicable in the conduct of study.

\section{1: Conceptualizing cultural ecology and drives}

Although there are common points of meeting and orientation, cultural ecology has been understood in its diversity. While Lapka at al. (2012) defined contemporary cultural ecology as a scientific approach reflecting the relationship between human society and the natural environment, Sutton and Anderson (2010), contextualized that concept as the study of the ways in which culture is used by people to adapt to their environment. This extends the concept to other areas of relationships between the man and nature debates in the process of sustainable livelihood in all contexts. Banks (1992) explained that cultural ecology as a research paradigm grew out of theoretical developments in many different fields such as biological ecology, geography, cultural anthropology, psychology and economics. In a very simplistic manner, Sarudam (2015) further summarize cultural ecology as the interaction of mind and materials with technologies and nature. What is critical in the definition is the aspect of adaptability, where cultural technologies are deployed by people in the process of adaptability. Cultural beliefs about ecological properties, whether physical or psychological, can act as motivators to patterns of behavioral expressions while using the ecosystem as a utilitarian facility. Cultural ecology manifests in different ways due to the recognition that present-day environmental problems have different antecedents and specific cultural forms are required as sustainable responses. Steward (2005) emphasized the need for cultural ecology to pay primary attention to empirically analyzed features of culture that promote the normatic utilization of the environment. Considering that culture, which is a human product, is subject to the processes of the mind and the material (Saradum, 2015), cultural ecology has been presented from the physical and mental dimensions.

Steward (2006) defined material culture in terms of exploitative or productive technology of the environment including subsistence devices such as weapons and instruments for hunting and fishing; containers for gathering and storing food; transportational devices used on land and water and sources of water and fuel. Material dimension of culture has been perceived in terms of goods, utensils, practices and institutions created to face natural or objective physical circumstances (De Bostus, 2009; Sarudam, 2015). Since people are very much interested in materialism, attraction to material ecology is a cultural pattern highly expressed in many communities. With regard to man-nature interface, the relationship between the physical and the psyche cannot be over sighted in bridging between abusive exploitation and environmental values. Steward (2006) was emphatic that behavior patterns involved in exploitation in the process of adaptability should be analyzed, and this extends to the cognitive dimension of ecology, which is equally perceived as spiritual or symbolic. Sarudam (2015) further clarified that culture in the forms of religious and symbolic concepts are known as the mental dimension of cultural ecology. Mental ecology builds on the premise that cultural ecology with great concern for materialism does not absolutely respond to the sustainable development of ecological mindsets in the process of preserving the earth's ecosystem. The spiritual and symbolic dimensions are made up of norms, ideas, interpretations, beliefs, traditions, expectations, aspirations, indigenous ecological knowledge values that serve specific human functions. The challenge of this dimension is to understand how human cognitions such as attitudes, perceptions, imagery has brought about ecological crisis in the process of building a sustainable society and opportunities therein. Despite the fact that physical cultural ecology is visible and easily used to achieve certain ends, the spiritual and mental perspectives cannot be undermined in the process of realizing economic activities.

Although environmental characteristics have been recognized as capable of ensuring occupational activities, the idea of human agency and motivation in particular is critical in the current analysis. Motivation is often defined in terms of needs, wants, drives, or impulses within the individual and in other words understood as the "whys" of behavior. To Bastic and Gojcic (2011) motives are inextricably linked to expected outcomes of behaviour and internal motive is associated with drives, feelings, and instincts as well as involves mental representations such as knowledge or beliefs. The motivation of fishers to preserve or destroy the ecosystem depends on the strength of their motives, which anyway, are as diverse as their needs. 
This implies that mental and cultural technology values are core factors in motivation considering that they are highly associated with belief systems of fishers in both social and economic life.

\subsection{Theoretical framework}

Despite diversities and differences in cultural attributes, and ongoing tension between occupational interest and environmental justice, many theories have been advanced to explain existing relationships between man and the ecosystem. Apart from cultural ecology frameworks, some behavioral models have been proposed. Kurt Lewin (1951) defined the "field theory" in terms of behavior, personality and environment. In his attempt to explain the relationship, Lewin advanced a basic formula: " $\mathrm{B}=\mathrm{f}(\mathrm{PE})$,", where $\mathrm{B}=$ behavior; $\mathrm{F}=$ function; $\mathrm{P}=$ personality and other individual factors and $\mathrm{E}=$ perceived environment of the individual. Taking forward the field theory, Barker (1963), coined the term "behavior setting" as a standing pattern of behavior-and-milieu, to account for the outcome of relationship between behaviour and environment in a particular situation and structural characteristics with visible episodes within ecological units. Baker studied behavior "in situ," with all the complexity of factors that shaped it, and observed that most often behavioral outcomes can be predicted more accurately on the basis of the situation in which they occur, rather than on the grounds of their personality (Popov \& Chompalov, 2012). Emphasis has been laid on the properties of the environment and how it can influence behavior, and the interaction between personality and action in a given milieu.

The current study deploys the concept and method of cultural ecology as analytical framework. Nevertheless, it builds on existing psycho-ecology models with emphasis on the utilitarian nature of cultural patterning in adaptive processes. Julian Steward (1955), proposed "The Concept and Method of Cultural Ecology" as an approach to understanding how humans use culture to adapt selectively to a variety of environments in society. This is known as cultural patterning, and to Gunn (1980), the approach is an operational tool rather than an end in itself. The theory of cultural change holds that human adaptation involves the technologies, practices, and knowledge that allow people to live in an environment (Steward, 2005). The theory sought to understand the cultural responses underpinning, and resulting from, human adaptations to changing environmental conditions using cultural patterns such as indigenous knowledge values and rituals. Interest is on the particulars of environments, rather than on general principles of cultural-environment situation (Gunn, 1980). It attempts to explain particular cultural patterns in particular locales, and demonstrate its functionality to survival strategy. Steward's methodology takes into account three procedures: (1) Document the technologies of culture and how they interact with the environment in the process of adaptation.(2) Examine patterns of human behaviour that are associated with the use of the environment. (3) Assess how much these patterns of behaviour influenced other aspects of culture or exploitative behaviour. Since cultural change has become a central tenet, and a driving force in understanding the framework of technology and role adaptability, cultural ecology represents the ways in which culture change is induced by adaptation to the environment (Steward, 2005). The culture-fitness of the theory is evident considering that in an attempt to adapt to the environment, fishers are using both material and mental cultural ecology to serve certain functions as they strive for sustainable livelihood.

\subsection{Related literature}

De Bustos (2009), presented material dimension of cultural ecology comprising information technology, markets and political organizations as institutions that are functional in the fulfillment of life. This means that occupational choices and patterns are derived from cultural ecology through mental and behavioral actions and should be perceived as valuable in adaptive processes. While exploring positive spiritual environment and pro-ecological practices, Barrera-Hernandez et al. (2015) found that material elements that surround and sustain daily life such as streets, schools, churches, homes, rooms and work are perceived as sacred, and significantly influence people's way of thinking, feeling and behaviour. It stands that such settings are capable of determining the actualization of programmed behaviors, and this is evident in the responses to change processes in economic activities. Such cultural patterns determined adaptive strategies of a people as they respond to livelihood challenges. Jena et al. (2017) observed that environmental influences have fundamentally been a by-product of materialistic desire deployed for deriving personal security, power, status and physical comfort. It means that the value of materialism has inherent ecological drivers and capable of energizing the behaviour of actors as well as exerting a recommendable degree of influence on pro ecological attitudes and behaviour towards a sustainable future.

Despite the adaptive functions of physical ecology, mental cultural ecology upholds that heritage is not only a set of natural reserves, but artifacts or properties embedded with meaning. 
According to De Bustos (2009), mental ecology consists of ideas, interpretations, beliefs, traditions, aspirations and serves other functions that affect people and the environment. This no doubt explains the cognitive dimension of cultural ecology as a core psychological resource that is instrumental in the achievement of human needs in a given milieu. Using a Mix method design, Crowe (2013) examined the impact of spirituality on environmental attitudes and actions, and eco-spirituality was capable of increasing knowledge and awareness about the earth's eco-system, and skills to ensure stewardship of the ecosystem. Investigating the conception of spiritual environment and characteristics of places, Barrera-Hernandezet al. (2015), reported spiritual environment as significantly related to sacred, nature, cleanliness, tranquility, harmony, happiness and wellbeing. This is enough evidence that mental cultural ecology is capable of promoting human wellbeing and ecological resources. Furthermore, it demonstrates the force of mental ecology as determinant of other spiritual values capable of energizing eco-work activities. Closely related to the present study is the elaborate investigation of Poroch et al. (2009) with aboriginals of Australia. Using literature from 89 Australian reports, it was observed that Aboriginal people's concepts of social and emotional wellbeing intersect with concepts and experiences of spirituality. Results showed the capacity of spiritual traditions in supportive psychotherapy, which provide meaning and identity, and assisted in building resilience in patience of mental health disorders. In addition, traditional healers were observed to have incorporated spirituality in their healing practices. Thus, mental cultural ecology is invaluable in professional settings, and this has been integrated by Bamabalang fishers as energizers in their occupational practice. Based on background orientation, theoretical and empirical literature on cultural ecology and livelihood behaviour, and the cultural patterning of fishers in Bamabalang community, the study intends to test the following assumptions:

Hypothesis 1: Physical cultural ecology will exert a direct positive influence on occupational motivation of inland fishers

Hypothesis 2: Mental cultural ecology will exert a direct positive influence on occupational motivation of inland fishers

\section{Methodology}

This section presents the approaches and materials used in the conduct of the investigation. The study was carried out in Bambalang village, a fishing community located some $25 \mathrm{KM}$ from Bamenda, North West Regional headquarters.

\subsection{Population and Participants}

The population for this study was made up of fishers who lived in Bambalang and its environs. These were individuals who consider fishing as a primary occupation, and also those who did fishing alongside other activities. Using convenient sampling technique, 130 fishers (35.7\%females, 64.3\% males), age range 19-51 $(\mathrm{M}=29.02 ; \mathrm{SD}=10.24)$ were used. Young fishers age 26-30 (26.2\%) dominated the activities, followed by 31-35 age group (24.6\%). Majority of participants were primary school graduates $(41.1 \%)$, and this was closely followed by secondary school leavers $(22.5 \%)$. Some fishers were University graduates $(10 \%)$, and these were those on holidays, and a few graduates still prospecting formal employment. Following participants' level of education, they could express themselves fluently in "Pidgin-English", local English language understood and spoken by people the community. Since the topic was cultural and too sensitive, the investigators started with a contact visit to the palace to explain the raison d'être of the study, and to obtain consent and blessings from the village authority. A guide was then put at our disposal by the community, who was briefed on the goal, processes and ethics of the investigation. Following the adoption of the ethical codes of the American Psychological Association (APA), appropriate provisions were discussed and agreed upon. Data gathering started with a random pick of fishers in the community who were not by the fishing site. Participants were informed of the nature, purpose and procedure of the study, content of the questionnaire, approximate time allocation, and how the research project would benefit them. Despite their level of education, majority were assisted in administering the instrument. Descriptive analysis was used to establish mean and standard deviation with regards to the variables while regression analysis was used to test the relationships.

\subsection{Data collection instrument}

The study deployed a Likert-type questionnaire with quantitative and qualitative options for information gathering. The questionnaire had four sections for material and spiritual cultural patterns (mental and material cultural ecology), motivation and demographics. 
The subscale for physical cultural ecology, 8 items, explored chewing of herbs, robbing of camwood, ritual dancing, water cleansing libation, rings for good luck, bangles for good luck, use of red feather and the use of talisman. Sample items: "Chewing special herbs encourages fishermen to go fishing", "Using camwood calls for recognition from the gods", with internal reliability coefficient of .72. The sub-scale for mental cultural ecology, 7 items, explored information on mind-body purification, sacrifices to god, good luck donation, songs of attraction, knowledge in fish attraction, knowledge of fishing seasons and techniques of net manipulation. Sample questions: "Offering sacrifices to the gods is a common practice by fishers", "knowledge of fishing techniques is essential in doing fishing", and the alpha for the subscale was .64. The subscale for motivation, 11 items collected information on status, money, security, wealth and subsistence, pleasure seeking, challenges, achievement, learning, recognition and role model. Sample questions: "I work to be recognized as a professional fisherman", "I do fishing to provide for my basic needs" with internal reliability coefficient of .79. The instrument also had a section for demographic information: age, sex, marital status and educational level. Using the 5-point scale, participants indicated the most appropriate option, and filled the most appropriate responses in the open questions. Participants were given the opportunity to ask questions when necessary, and with such cases clarifications were made. Of all the 150 questionnaires administered, 130 were used giving a response rate of $86.66 \%$. In some cases palm wine (local liquor) was provided to fishers as they persistently requested for incentives for their participation in the exercise.

\section{Results of the Study}

The study examined the association between cultural patterns and occupational drives of fishers. Pearson correlation analysis was performed between the independent variable (mental and material cultural ecology) and the dependent variable (motivation) as presented in Table 1. Results showed a significant positive correlation between mental cultural ecology and material ecology $(r=.269, \mathrm{p}<0.0)$, and fishing motivation $(r=.337, p<0.0)$. In addition, the relationship between material cultural ecology and fishing motivation was also reported as significant $(\mathrm{r}=.337, \mathrm{p}<0.0)$. The significant results suggest that the variables are mutually reinforcing, where an increase or decrease in a given variable will have a corresponding effect on the other. For instance, increased in level of mental and material cultural ecology will increase the level of fishing motivation. Descriptive analysis isolated motivation as having the highest mean value $(\mathrm{M}=34.22 ; \mathrm{SD}=7.18)$ as compared to mental cultural ecology $(M=24.23 ; S D=5.06)$, and material cultural ecology $(M=23.58 ; S D=5.36)$. This shows that fishers were highly motivated to perform their occupational activities given the different cultural patterns. A higher mean for mental cultural patterns suggests that it can be more influential in the drives of fishers as compared to material cultural ecology. With regards to scale reliability coefficient, the Cronbach Alpha ranged from .64 to .79 for subscales, with an aggregate score of .71 which was considered as acceptable.

Table 1: Bivariate correlation analysis and descriptive $\mathrm{N}=130$

\begin{tabular}{|c|c|c|}
\hline Variables & 2 & Std. DevAlpha \\
\hline Mental cultural ecology (1) & 1 & 24.23085 .06782 .64 \\
\hline Material cultural ecology & $.269^{* * 1} 1$ & 23.58465 .36683 .72 \\
\hline Fishing Motivation (3) & $.337^{* *} .344^{*}$ & 34.22317 .18878 .79 \\
\hline
\end{tabular}

The first hypothesis investigated if physical cultural ecology can predict occupational motivation of fishers, and results have been presented in Table 3. According to regression $11.8 \%\left({ }^{\mathrm{R} 2=} 0.118\right)$ of the variations on motivation of fishers can be explained by material cultural ecology $(\beta=0.34 .4, \mathrm{t}=41.142, \mathrm{P} \leq 0.05)$, while the other $88.2 \%$ explained by other factors. It is therefore evident that a unit change in material cultural ecology increases fishers' motivation by 0.461 units. With regards to the fitness of the model, results show that it was significant (Fvalue=17.157; $\mathrm{P}<0.05)$ in testing the assumptions of the study. Results confirm the first hypothesis $(\mathrm{Ha})$ that material cultural ecology has a significant effect on motivation of fishers in a local community.

Table 3: Regression between material cultural ecology and motivation of fishers

\begin{tabular}{lclllll}
\hline $\begin{array}{l}\text { Predictor } \\
\text { Variable }\end{array}$ & \multicolumn{2}{c}{$\begin{array}{l}\text { Unstandardized } \\
\text { Coefficients }\end{array}$} & $\begin{array}{l}\text { Standardized } \\
\text { Coefficients }\end{array}$ & $\begin{array}{l}\text { Sig. 95.0\% } \\
\text { for B }\end{array}$ & Confidence & Interval \\
& B & Std. Error & Beta & \multicolumn{2}{c}{$\begin{array}{l}\text { Lower Bound } \\
\text { Bpper Bound }\end{array}$} \\
Material & cultural23.362 & 2.689 & & 8.689 .00018 .042 & 28.682 \\
ecology & .461 & .111 & .344 & 4.142 .000 .241 & .680 \\
\hline
\end{tabular}


Note: ${ }^{\mathrm{R}=} 0.344 ;{ }^{\mathrm{R} 2=} 0.118 ;$ Adj. ${ }^{\mathrm{R} 2=} 0.111$; Sig. $\mathrm{F}=0.000 ; \mathrm{F}$-value $=17.157$; Motivation; $\mathrm{p}<0.05$

The second assumption tested if mental cultural ecology can determine occupational motivation of fishers of Bambalang. A simple regression was performed to determine the effect on motivation, and results presented in Table 2. Results revealed that $11.3 \%\left({ }^{\mathrm{R} 2=} 0.113\right)$ of the variations on motivation of fishers can be explained by mental cultural ecology $(\beta=0.337, \mathrm{t}=4.045, \mathrm{P} \leq 0.05)$, while the other $88.7 \%$ can be explained by other factors. This therefore implies that a unit change in mental cultural ecology increases fishers' motivation by 0.478 units. Results also indicated that the model was a good fit $(\mathrm{F}-\mathrm{value}=16.365 ; \mathrm{P}<0.05)$ and significant in testing the hypothesized relationships. Results confirm hypothesis two (Ha) that mental cultural ecology has a significant effect on occupational motivation of fishers.

Table 2: Regression between mental cultural ecology and motivation of fishers

\begin{tabular}{|c|c|c|c|c|c|}
\hline \multirow{4}{*}{$\begin{array}{l}\text { Predictor } \\
\text { Variable }\end{array}$} & \multicolumn{2}{|c|}{ Unstandardized } & Standardized Coefficients t & Sig. $95.0 \%$ & Confidence \\
\hline & \multicolumn{3}{|c|}{ Coefficients } & \multicolumn{2}{|c|}{ Interval for B } \\
\hline & B & Std. Error & Beta & \multicolumn{2}{|c|}{ Lower Bound Upper } \\
\hline & & & & & Bound \\
\hline \multirow{2}{*}{ Mental cultural ecology } & 22.651 & 2.922 & & 7.751 .00016 .869 & 28.432 \\
\hline & .478 & .118 & .337 & 4.045 .000 .244 & .711 \\
\hline
\end{tabular}

\section{Discussion of Results}

The study was designed to investigate the effect of mental and material ecology on the occupational motivation of inland fishers with the understanding that cultural patterning is an adaptive mode fostering work behavior and ensuring sustainability. It was reported that both variables (material and mental ecology) constituted adaptive measures capable of energizing local fishers towards sustainable fishing ventures. The relationships among mental cultural ecology, material cultural ecology and motivation were highly significant concurring with cultural patterning and adaptive values (Sarudam, 2015; Steward, 2006), material ecology and survival strategies (De Bustos, 2009; Saradum, 2015), and cultural ecology and preservation of the earth's ecosystem (BarreraHernandezet al., 2015; Sutton and Anderson, 2010) with particular focus on aquatic and marine biodiversity (Chambers, 1999; Forgako, 2017; Mmbaga, 2013). However, the present results extend to past studies by drawing cultural patterns closer to local work values, and how cultural technology can determine sustainability of fishery activities. Though conceptualizations and findings are beyond local contexts, lessons in cultural patterning are drawn, and applicable in fostering ecologically relevant behaviors in artisanal fishing. Analysis of the first hypothesis showed that material cultural ecology significantly influenced occupational motivation of inland fishers. This suggests that material cultural patterns are adaptive modes to the demands of the environment, and capable of driving fishers towards the achievement of their occupational needs and desires. Results agree with Sutton and Anderson (2010) who found material cultural patterns as livelihood strategies. This is of critical importance to fishers considering that giving meanings to material values is designed to satisfy certain needs, and these values act as catalysts to occupational interest of fishers. This concurs with De Bustos (2009) that material values serve the function of needs fulfillment to human beings in any endeavor. Results are also consistent with Barrera-Hernandez et al. (2015) that material elements surrounding and sustaining daily life are perceived as sacred, and significantly influences behaviour of people. Consequently, sustainable work behaviors cannot be excluded, and inland fishers of Bambalang cannot undermine the use of material cultural patterns in their occupations. Furthermore, results are similar to Jena and Behera (2017) who reported materialistic desires as capable of moving people's behaviour towards respective ends. It is therefore evident that material patterns as artifacts could be used for protection or to calm water for productive fishing and this can move fishers to work. Although supporting studies were out of local context, they confirm that fishers are naturally driven by these factors in order to work in harmony with the realities of nature.

The study also established mental cultural ecology as a predictor of motivation of fishers, and findings were consistent with De Bustos (2009) that mental ecology consists of aspirations and serves appropriate functions that affect people and the environment. This suggests that the cognitive dispositions of fishers in terms of cultural practices could be enhanced to promote sustainability of fisheries in the community. 
This agrees with Crowe (2013), who found that eco-spirituality increased knowledge and awareness about the eco-system, and promoted skills to ensure stewardship of all aspects of the environment. With this recognition, it is normal for fishers to hold tight to their cultural values as utilitarian facilities for ensuring sustainability of fishing business. Results are in total agreement with Poroch et al. (2009) that indigenous spiritual traditions support occupational practices in psychotherapy and promote resilience in patients suffering from mental health disorders. This shows a direct effect on occupational practices suggesting that cultural beliefs and practices are occupational drivers of fishers. If traditional healers could incorporate cultural technology into their healing practices, there is no doubt that fishers can use it same in their occupational practice.

\subsection{Implications of the study}

The results of the investigation contribute to the body of theoretical and empirical knowledge in cultural ecology with particular reference to occupational motivation in the fishery sector. It also contributes towards bridging the gap between economic and eco-cultural interest for necessary sustainability. Government intervention is visible, but policy strategies promoting inland fishers should be enabling, and embrace cultural diversities that can build sustainably on the realities of fishers. There are no doubt regressive technologies drawn from irrational economic motives and exogenous models to promote sustainability. In this respect, behaviour change is essential to build homegrown knowledge infrastructure of fishers to flexibly embrace relevant conventional values. This is possible with the recognition that customary laws, shared values and belief systems constitute an integral part of local people's lifestyle with inbuilt eco-values, and local people respond appropriately to diverse environmental conditions and potential risks by developing indigenous strategies (Fomba, 2012). This advocates that implementation strategies need to identify survival cultural patterns of fishers as utilitarian strategies capable of building eco-work behaviors that can promote sustainable management of aquatic resources. However, this is a challenging venture, but upgrading the skill base of field agents with indigenous knowledge values is an optimistic measure. The competitive advantages of fishery co-management currently practiced with fishers have an inbuilt sustainability mechanism that can improve operations of inland fishers and protect the ecosystem.

The use of cultural patterning in catalyzing behaviour of inland fishers implies working in harmony with nature, and this is recommendable considering that it is available and cost-effective to adopt in sustainability demands. Although cultural ecology is under increasing threats of disappearing as a result of both biophysical and social changes (Madakan et al. 2015), fishers have internalized their cultural values and integrate them into their fishing culture. They believe in what they own, whether mental or material, it appears to be an urge to get what they need, and this could be explained in terms of fishing energy. Consequently, the promotion of green values is indispensable, while the deconstruction of regressive eco-values critical. With the cognizance that the challenge of cultural ecology is to understand how human cognitions have brought about environmental crisis in the process of building sustainable actions (Jena and Behera, 2017), working in harmony with nature becomes an adaptive mechanism, which is indispensable in ensuring a sustainable future for fishery activities in Bamabalang.

Results can also be used to design more effective policies, and institutional actions to improve and increase cultural technologies that will promote environmentally friendly behavior of fishers. It is essential for the Ministry of tutelage and other stakeholders to allocate more resources for education and training of fishers. This is to introduce new technologies as well as recuperate endangered beliefs and practices to enable them have proenvironmental attitudes in their operations. Consequently, appropriate educational programs and campaigns with the community of fishers will cultivate awareness, and a positive green mental culture capable of fostering sustainable work behaviors. It would be necessary to reiterate that cultural ecology is interested in adaptive behaviour of organisms and a strategy to respond to sustainable livelihood in the environment (Sutton and Anderson, 2010). Findings should not escape the attention of promoters of artisanal fishers in their activities. The preservation of indigenous peoples and their traditional cultures must play a central part in the conservation of marine and aquatic biodiversity that they depend on and in turn sustain their living (Chambers, 1999). To this effect, cultural ecology stands as a functional utility in driving occupational behaviour of fishers, and should be encouraged to bridge the widening gap between immediate and ultimate interest of fishers.

\subsection{Conclusion}

The study recognized that cultural technology can significantly influence occupational drives of fishers towards a sustainable future. Evidences from analysis suggest that a creative and innovative approach is required in order to integrate eco-cultural values into modern fishing technologies in order to promote sustainability in the occupation, 
and cultural patterning is a viable response. Mental and physical cultural ecology are deployed as predictors of fishers' motivation and reinforcing related positive values is recommendable. Since local communities often have a detailed knowledge of their environment, local peoples can, and indeed must, play a central role if marine and aquatic resources are to be effectively conserved (Chambers, 1999). Although the ultimate benefits of fishing may not be easily discerned, it is a great challenge to fishers to understand the motives behind their activities and the criticality of promoting biodiversity in the Bamabalang Lake to sustain the occupation and livelihood drives. There is no doubt that the value system has been found as a prima-facie for shaping intrinsic motivation (Jena and Behera, 2017), and this expresses a need to define a sustainable pathway, which is sensitive enough to the reverence of marine ecology. The fishery management practices which are culturally eco-sensitive constitute a key strategy capable of healing the disjuncture between work and nature. Local communities are generally blessed with abundant resources with a wealth of green opportunities and awareness creation and skills development are necessary to enroll many on board the green economy platform (Fomba, 2012). This appears a great challenge to stakeholders and enrolling fishers on board preferred cultural technology will promote pro environmental behaviour, and also engineer sustainability of the occupation. Despite the fact that the present investigation adds value to scarce materials in cultural ecology, it relies solely on quantitative information and triangulation of results with qualitative approaches was not involved. There is a possibility that some respondents might have become too sensitive to indicators of cultural ecology, and faced problems of disclosure to "outsiders", particularly with the sacred and secret practices. The question of ecological validity could also be raised considering that only a single occupational activity and community were isolated for the study. There is dire need to extend studies to other occupational sectors, communities, and deploy mix-methods. Physical and mental cultural ecology could in future be explored to understand relationships with risk perception, safety, health behaviors and life satisfaction. Despite the limitations, the study appears to be one of the scarce attempts in the domain of work psychology, drawing in cultural technology to analyze the force of cultural patterning in energizing occupational behaviour and ecological sustainability of the fishery sector.

\section{References}

Al-khawaja, A. (2015) Environmental auditing: Modeling Office Workplace Ecology, PhD thesis, Faculty of Society and Design, Bond University Gold Coast, Queensland Australia, retrieved on 23/08/18 from

https://epublications.bond.edu.au/cgi/viewcontent.cgi?article $=1168 \&$ context $=$ theses

Banks, E. P. (1992) An integrated strategy for the study of the cultural ecology of Mongolia, A Paper Prepared for the Nomads' Route International Expedition and Seminar, 3-5 August,Ulaanbaatar, Mongolia.

Bastic, M. \&Gojcic (2011).The ecological motivation of tourists as a determinant of the tourists' loyalty, Croatian Operational Research Review (CRORR), 2,14-22

Barrera-Hernandez, L.F., Corral-Verdugo, V., Tapia-Fonllem, C.O. \&Fraijo-Sing, B.S. (2015), "Psychological meanings of "positive spiritual environment" and "places to communicate with god", European Scientific Journal, 11 (26) 357-369

Brenner, J. E. (2018), The Philosophy of Ecology and Sustainability: New Logical and Informational Dimensions, Philosophies, 3(16),1-25

Chambers, P. (1999), Aquatic and marine biodiversity, in Posey, D.A. (Ed), Cultural and Spiritual Values of Biodiversity, (397-434), UNEP: Nairobi

De Bustos, J. C. M. (2009) Cultural Ecology, In Culture, Communication and Ecology, Retrieved on 3/7/201at: retrieved at http://www.infoamerica.org/icr/n01/infoamerica01bustos.pdf

Cacaud, P. and Cosentino-Roush, S. (2016) A How-to Guide on legislating for an ecosystem approach to fisheries, FAO EAF-Nansen Project Report No 27. Rome, Italy.

Clovis, C. (2003) Ecology at Work: The Biodome Challenge, Science Education Review, 2(2), 553-558

Crowe, J. L. (2013) Transforming Environmental Attitudes and Behaviours through Eco-spirituality and Religion, International Electronic Journal of Environmental Education, 3 (1), 75-88

Fomba E. M. (2012) Building ecological entrepreneurship: creating environmental solutions based on the cultural realities and needs of local people, Journal of Environmental Investing, 3(2) 43-62

Forgako E. G. (2018). Techniques of controlling mixed sex tilapia and the practicability of hormonal reversal in Cameroon. Nations University Fisheries Training Programme, Iceland, Retrieved on 08/18 at:http://www.unuftp.is/static/fellows/document/elizabeth16prf.pdf 
Gunn, M. C. (1980) Cultural ecology: a brief overview, Nebraska Anthropologist,149, 18-27

Jena, L.K. \&Behera, B. (2017).Environmental crisis and human well-being: A review, International Journal of Development and Sustainability, 6 (8),561-574.

Lapka, M., Vávra1, J \&Sokolíčková, Z (2012) Cultural ecology: contemporary understanding of the relationship between humans and the environment, Journal of Landscape Ecology, 5(2), 12-24

Madakan, S. P., Ladu, B.M., Neiland, A. E. \&Sarch, M. T (2015) Characteristics of the Social-ecological System Components of Three major Artisanal Fisheries in the North East of Nigeria, Nigerian Journal of Fisheries and Aquaculture, (3)1\&2, $22-33$

Mmbaga, T.K (2013)The effect of fishing on the ecology of sea cucumber (Holothuroidea: Echinodermata) Holothuriascabra and Holothurianobilisin Tanzanian sea water", International Journal of Development and Sustainability, 2 ( 2), 1099-1126

Popov, L. \&Chompalov, I (2012) Crossing Over: The Interdisciplinary Meaning of Behavior Setting Theory, International Journal of Humanities and Social Science, 2(19)18-27

Saradum, N (2005) Buddhist Approaches to Cultural Ecology by Means of Virtue Ethics", Journal of International Buddhist Studies, 6(1) 75-83

Sutton, M., Q \& Anderson, E. N (2010) Introduction to cultural ecology, Rowman\& Littlefield Publishers, Inc: Toronto.

Steward, J. (2006)The Concept and Method of Cultural Ecology, In Haen, N. \&Wilk, R., The Environment in Anthropology: a reader in ecology, culture and sustainable living, New York: New York University Press

Poroch1, N., Arabena, K., Tongs, J., Larkin, S., Fisher, J. \& Henderson, G. (2009) Spirituality and Aboriginal People's Social and Emotional Wellbeing: A Review, Discussion Paper Series: No. 11, Cooperative Research Centre for Aboriginal Health, Casuarina, Australia

Posey, D. A. (1999) Introduction: Culture and Nature - The Inextricable Link, in Posey, D.A. (Ed), Cultural and Spiritual Values of Biodiversity, (pp 1-18), Nairobi: UNEP 